\title{
In Press We Trust? A Comparative Study of Three European Press Systems
}

\author{
Antonio Ciaglia \\ Correspondence: Antonio Ciaglia, SUM - Italian Institute of Human Sciences, Florence, Italy. E-mail: \\ antonio.ciaglia@sumitalia.it
}

Received: September 18, 2013 Accepted: October 8, 2013 Available online: October 22, 2013

doi:10.11114/smc.v1i2.223

URL: http://dx.doi.org/10.11114/smc.v1i2.223

\begin{abstract}
For the vast majority of the citizens in today's advanced democracies, the media, in particular traditional media, represent the only window that can be opened daily into current public and political debates. In fact, a very small fraction of the population is actually able to experience politics directly. Consequently, it becomes crucial that those means - the media - that are assigned to keep citizens informed about politicians' management of public affairs obtain a sufficiently higher degree of trust from citizens. By comparing three press systems in the UK, Germany, and Italy, this manuscript aims to expose and explain the types of connections that can be established between the structural features of modern European press systems and the degree of trust in how the press performs. More specifically, particular attention is paid to the links between people's attitudes and the degree of pluralism achieved within the print media sector in fast evolving media environments.
\end{abstract}

Keywords: print media, trust, press market, media systems, comparative research

\section{Theoretical Background}

In political and social sciences, the concept of trust is rarely associated with the media and its outputs. Easton (1979) elaborates on two types of support related to political systems: specific and diffuse support. Each support type is characterized by particular features, which help qualify and differentiate the two. However, a particularly important element of Easton's conceptualization can be found in the varying effects that the lack of specific and diffuse support can have on the entire political system. For example, when a given political system is characterized by a high degree of mistrust, the public authority and the measures it implements will most likely be viewed with extreme dissatisfaction. Not only can such generalized discontent lead office holders to step down, thereby permitting the mechanism of democratic accountability to work properly, but it can also create conditions for marked and profound socio-political change (Easton, 1979). Under different circumstances, dissent can translate into a loss of legitimacy for a political regime and its leaders, particularly in terms of their ability to adequately respond to community needs and expectations. In such cases, radical socio-political change is unlikely to occur (Easton, 1975). Easton concludes that disaffection does not always generate the same effects on the political system in which it takes root. Under certain circumstances, discontent can be aimed at office holders and the outputs of their political action. Alternatively, disaffection can affect the very basic elements of a given system-its pillars, which are the rules of the game. When these core components are called into question, dissent is much deeper and more "diffuse."

The nature of trust that people have (or lack) in the media is considerably different from citizens' attitudes toward the government and/or other political institutions. The media studies field is characterized by a long-standing debate regarding the substantial role that the media play within modern democracies. More specifically, several studies have examined the impact that print and audiovisual news media can have on citizens' levels of participation in political life and their degree of trust in political institutions as a whole. However, research has revealed contradictory results. Some scholars have sought to identify a possible direct (or inverse, depending on the hypotheses) correlation between news media consumption and democratic participation, civic engagement and trust in institutions.

Because many countries today are highly populated, forms of direct democracy are often difficult to implement. Not only do democratic citizens need to delegate decision-making power to elected representatives, but they are also asked to rely on the media to acquire knowledge about political and policy debates that they cannot directly 
access. Accordingly, if the media (and the information they provide) are not considered to be credible and are mistrusted by the citizens, then citizens' opinions of their political systems risk being profoundly undermined. Dahl (1967) interestingly notes that due to population increases, the forms of communication between political leaders and citizens become more blurred and indirect. Moreover, this communication tends to become increasingly asymmetrical. Indeed, while radio and television allow a more direct "contact," they also favor the establishment of a unidirectional, one-to-many flow of communication (Dahl, 1967). The widening gap between leaders and citizens also represents one of the contributing factors to the rise of democratic malaise across America and Europe. Several years after Dahl, Robinson (1976) introduces the concept of videomalaise, namely a form of disaffection toward politics that television engenders more than other media do. According to Robinson, television, unlike print media, tends to negatively frame the events it covers, emphasizing aspects related to violence and conflict. Therefore, following McLuhan (1964), Robison argues that television is a force for social change and development, although it can generate forms of malaise due to its tendency to sensationalize the topics it covers. Because of this tendency, television more adequately entertains than informs (Postman, 1985). Putnam (1995; 2000) views the expansion of television as a contributing factor to people's disaffection toward politics and to the steady "erosion" of American social capital. According to Putnam, television has privatized and individualized citizens' free time, to the detriment of social interaction. Other scholars (Patterson, 1993; Cappella \& Jamieson, 1997) have assumed a broader perspective, taking into consideration not only audiovisual media but also print outlets. Nonetheless, the conclusions they reach are similar: the media tend to pay much more attention to political fights and political party positioning than to the contents and consequences of political action. This tendency is likely to generate a snowball effect, potentially leading the public to grow cynical, disinterested, and ultimately apathetic toward the political system.

The last point shows that people's mistrust is not only focused on audiovisual media. Rather, such mistrust can also spread to the press. Indeed, some authors have noted that, similar to television, print media often tend to emphasize the most sensational features of a given topic. Accordingly, some authors are more inclined to use the concept of media malaise rather than videomalaise (Campus, 2008), as the degree of apathy and mistrust seems to be less dependent on the media type than on how people use the media (Newton, 1999a). However, although Newton notes that newspaper readers display a deeper knowledge of political debates and issues, his study does not confirm whether this deeper knowledge is likely to result in greater trust of the media and political institutions. Bennett et al. (1999), on the other hand, notes a connection between mistrust in institutions and high consumption of tabloid media. Other authors (Floss, 2008) highlight the role played by additional intervening variables, emphasizing that trust in institutions is not as dependent on media coverage as it is on people's own political preferences.

However, the media are not always the primary party responsible for the establishment of forms of civic disaffection and disengagement. According to Norris (2000), the theory of media malaise lacks sufficient clarity and fails to provide evidence of an effective correlation between media consumption and democratic malaise. This scenario is even more complicated by the existence of an extremely large number of moderating factors, such as party affiliation and the general state of the economy (Newton, 1999b). In her study, Norris finds that regular newspaper readers not only display a higher degree of awareness on political issues, but they also tend to be more confident in political institutions and to participate in political life to a higher extent than their non-newspaper reading counterparts. In the long term, Norris theorizes the activation of a "virtuous circle," in which media coverage and party campaigns function as mobilizing agents for those already mobilized. In other words, the media and party activism can be useful in increasing awareness in those citizens who already have a certain degree of interest in politics. Therefore, the media can trigger a virtuous circle if a certain degree of virtue already exists. Virtue can thus be increased but not generated. The central point in Norris's analysis is the rejection of a deterministic approach, by which watching television (or using any other medium) can have detrimental effects on the audience. In Norris's view, many of the media-generated effects are largely dependent on how those media are used by the public (Norris, 1996).

\section{The Research Framework}

While a number of studies about media malaise appear to be methodologically flawed, the results of Norris's research may be overinflated because only electoral campaign periods are taken into consideration. Indeed, during an electoral campaign cycle, it is likely that citizens' mobilization and participation rates increase. Nevertheless, the media do not work solely during electoral campaigns. Today's media systems are characterized by continuous inquiry and scrutiny toward office holders, which continues 24 hours a day, irrespective of whether elections are to be held in the near future. Given the media's constant monitoring of the political sphere, this research intends to specifically emphasize the link between (print) media systems' structural and professional features and citizens' trust in the press. This study will respond to the following research question: 


\section{What connections can be drawn between the degree of citizens' trust in the press and the structural characteristics of the press systems?}

This study's approach does not therefore specifically aim to elucidate the potential causal link between structure and perceptions. Instead, the objective is to identify whether, in advanced democratic contexts, different degrees of trust in the press can be associated with the different forms by which the press system is structured as well as with different journalistic practices and values. Furthermore, this article does not aim to add to the debate between media malaise and virtuous circle supporters. Such a debate is particularly focused on the trust that citizens do (or do not) have in political institutions and how different types of news media are likely to affect this judgment. Conversely, this article, aiming to maintain a degree of consistency with its structural approach, intends to explore citizens' trust (and the factors that have the potential to affect it) in only one political institution: the press (Cook, 1997; Blumler \& Kavanagh, 1999; Schudson, 2002). The research will rely on the comparative method, which is much underutilized in media studies (Blumler \& Gurevitch, 1995; Gurevitch \& Blumler, 2004; Hallin \& Mancini, 2004, 2012; Siebert et al., 1956; Pfetsch \& Esser, 2004) unlike in political science. The cases selected for analysis are the UK, Germany, and Italy. This selection relies on the well-known and widely accepted categorization of Western media systems elaborated by Daniel Hallin and Paolo Mancini. The authors identify three models, each of which displays unique features regarding how the media are structured and the role they are expected to play within society. More specifically, the authors look at four key dimensions within today's Western media systems: the structure of media markets, the degree of political parallelism, the degree of professionalization of journalism, and the role of the state. According to how such dimensions take shape and develop in each context, Hallin and Mancini draw three media-system models within the Western world: the Polarized Pluralist Model (which mostly established in Southern European countries), the Democratic Corporatist Model (which particularly applies to Central Europe and Scandinavia); the Liberal Model (which characterizes the UK, Ireland, Canada and the US). One country was selected per model.

In the first section, an overview of the structural features of three media systems is provided, with the aim of clarifying the various ways in which the oldest medium, the press, absorbs and reacts to the challenges launched by technological improvements and the rise of the new media. Particular attention will be paid to how differently the principle of media pluralism takes shape within the three press systems selected for analysis. The second section will be aimed at understanding whether different degrees of pluralism are associated with different degrees of trust in the press. The data analyzed will come from the last "wave" of surveys conducted by World Values Survey. A final caveat is paramount. Although this article focuses primarily on the press, television will also be examined as a privileged point of comparison. Two reasons stand behind this methodological choice. First, because the research scope is circumscribed to the so-called traditional media, it is not possible to fully understand the characteristics of the press system without considering the other massive pillar of today's media systems: television. Second, depending on the extent to which the level of trust between the two segments varies, it is possible to infer the underpinnings of the potential connections between the (media) structure and people's perceptions.

\section{Empirical Findings}

\subsection{The Press: Structural Analysis}

The concept of pluralism can be considered according to extremely different nuances, depending on whether it is applied to audiovisual or print media. In general, to be sufficiently plural, the press system does not require as strict rules as audiovisual media because of its structural characteristics and the high degree of maturity it has reached. In fact, although today's Western television systems are experiencing considerable growth in terms of proliferation of channels and technological platforms, TV pluralism still seems to be undermined by a number of dominant players who take full advantage of the renewed structural conditions. However, the extent to which such a threat becomes convincingly urgent is highly dependent on the nature of the context that one examines (Ciaglia, 2013). In general, TV markets are characterized by the presence of fewer players as opposed to the press systems. As this study will show, such a trend becomes even more marked in those countries, such as Germany and the UK, where mass-circulation press has a long-standing tradition. Such diverse traditions are fully reflected in the World Association of Newspapers' data with regard to daily newspapers' average readership. Overall, China and India are the countries with the highest daily circulation, whereas Germany ranks fifth (20 million copies), immediately behind the United States, the UK at sixth (14.9 million copies), and Italy at thirteenth (5.2 million copies). Such data, however, are strongly determined by the population differences in these countries; therefore, more detailed and cogent cues can be obtained by reviewing the average circulation per thousand inhabitants (Table 1). 


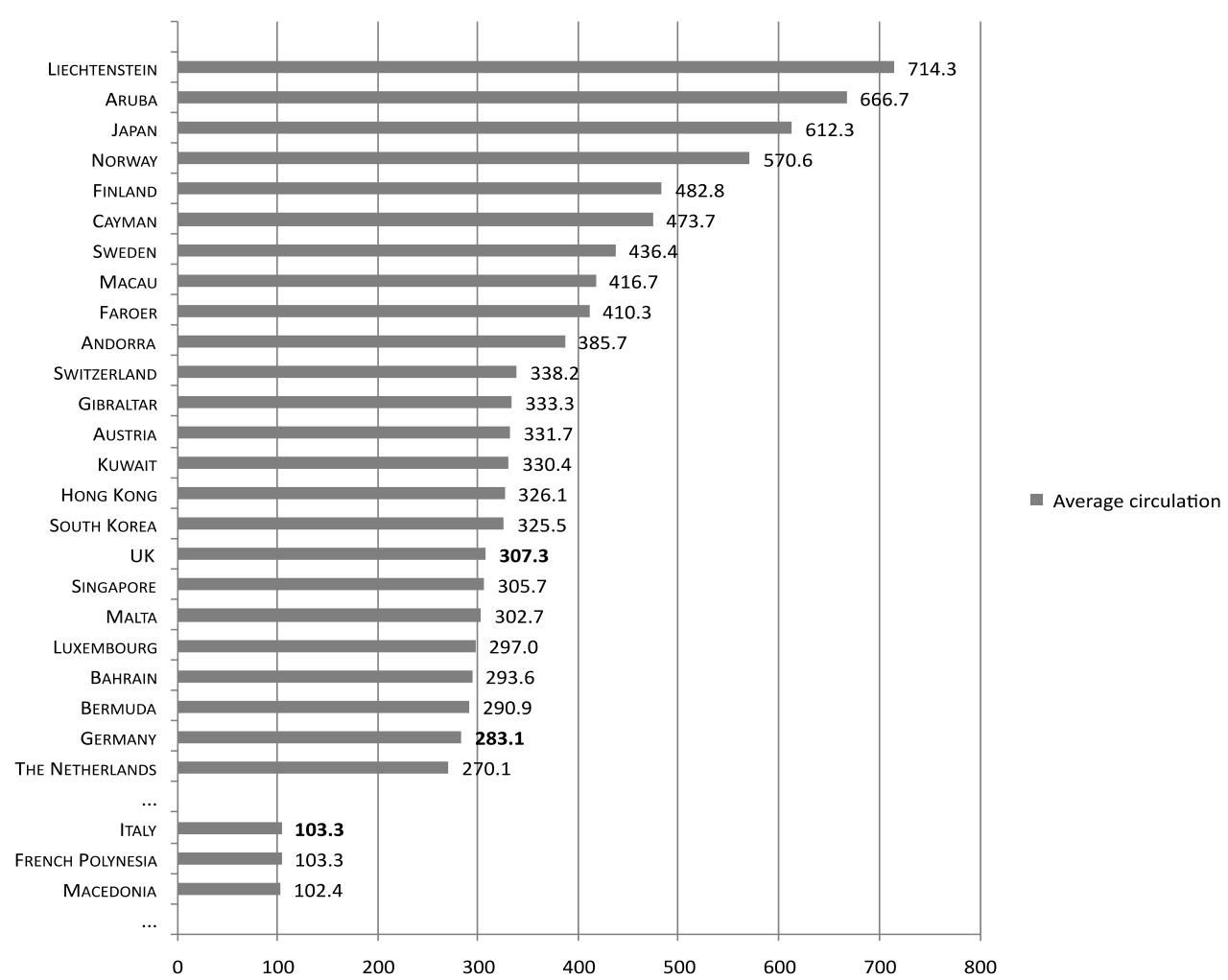

Figure 1. Paid-for dailies: Average circulation (copies per thousand inhabitants), 2008.

Source: World Press Trends, 2009.

Among the major advanced democracies, Scandinavian countries and Japan perform particularly well in terms of newspapers' average circulation. More specifically, in Japan, a country with nearly 130 million inhabitants, 666 paid-for daily copies are circulated per 1000 inhabitants. Regarding the countries selected for analysis here, the UK ranks seventeenth, although it would rank much higher if minor countries such as Liechtenstein, Aruba and others were not considered. Among the major countries, Germany (whose population is significantly higher than that of the UK and Italy) performs remarkably as well, ranking twenty-third with 283 copies per 1000 inhabitants. Italy (103 copies/1000) ranks far below the USA (200 copies/1000), Canada (159 copies/1000), Australia (147 copies/1000), New Zealand (198 copies/1000), and all other major Western European democracies with the exception of Portugal (67 copies/1000).

Other significant differences can be detected regarding the types of newspaper sales. In Germany, $64.8 \%$ of revenues drawn from newspaper sales are generated by subscriptions, while revenues from single-copy sales in 2008 accounted for $35.2 \%$. In both the UK and Italy, figures differ significantly. In the UK, $13 \%$ of revenues are drawn from subscriptions. In Italy, the proportion drops to 9\%. In all three countries, however, the TV sector is the larger media segment (including public service broadcasting). Nevertheless, in Germany and the UK, the press plays an equally relevant role, as evidenced by the significant advertising expenditures this sector garners.

Table 1. Advertising expenditures per medium, 2012. *

\begin{tabular}{|c|c|c|c|c|c|c|}
\hline & \multicolumn{2}{|c|}{ UK } & \multicolumn{2}{|c|}{ Germany } & \multicolumn{2}{|c|}{ Italy } \\
\hline & $E$ & $\%$ & $\boldsymbol{C}$ & $\%$ & $\boldsymbol{C}$ & $\%$ \\
\hline Newspapers and Magazines & 3,036 & 20.7 & 5,235 & 31.9 & 2,794 & 30.9 \\
\hline Television & 4,480 & 30.5 & 6,417 & 39.1 & 4,324 & 47.8 \\
\hline Internet & 5,420 & 36.9 & 3,151 & 19.2 & 817 & 9.0 \\
\hline Radio & 553 & 3.8 & 804 & 4.9 & 558 & 6.2 \\
\hline Outdoors & 970 & 6.6 & 574 & 3.5 & 492 & 5.4 \\
\hline Cinema & 213 & 1.5 & 230 & 1.4 & 57 & 0.6 \\
\hline Total & 14,672 & 100.0 & 16,411 & 100.0 & 9,042 & 100.0 \\
\hline
\end{tabular}

* Author's elaboration of data from Warc, Bvdv, and Agcom. Data for Italy and the UK refer to 2012. Data for Germany refer to 2011. 
At first glance, two key points emerge from Table 1. First, the resources spent on media advertising in Germany and in the UK are significantly higher than those in Italy. In fact, Italy's total media advertising expenditures are nearly half as much as they are in the other two countries. Second, regarding the itemization of media advertising expenditures, it is possible to say that the Italian case is basically a unipolar media system, in which television grabs nearly half of the total resources. Conversely, the British and German media systems could be more properly described as tripolar, with the majority of advertising resources distributed, albeit unevenly, among three dominant media segments: press, television, and Internet. It is particularly interesting to note that in Germany, the Internet grabs nearly one fifth of the overall expenditure, and in the UK the internet is the most important segment in terms of resources drawn (36.9\%); however, in Italy, such a voice still remains comparatively marginal at $9.0 \%$, attracting a proportion of advertising resources only $2.8 \%$ higher than radio.

Regarding the press's advertising expenditures, no major differences are present among the three countries. Indeed, in these three contexts, the press draws resources ranging from one fifth (UK) to slightly less than one third (Germany) of the overall resources. However, because of the difference in market size, expenditures on press advertising in Germany are nearly twice as high as those in Italy.

In terms of media advertising expenditures, in none of these countries is the press the medium into which the highest proportion of advertising resources are pumped. In fact, the dominant segment in the UK is the Internet, while television is the leading medium in both Germany and Italy. Indeed, although advertising is banned in British public service broadcasting (therefore, advertising expenditures are only channeled into the commercial broadcasters), both Italian and German public networks are allowed to broadcast commercial ads with certain limitations. However, by displaying a comparison of the distribution of advertising resources in 2007 and 2012 (2011 in Germany), Table 2 shows how rapidly and markedly the situation has changed in only five years, particularly with respect to Germany and the UK.

Table 2. Advertising expenditures per medium: Comparison 2007 - $2012(\%)$ * *

\begin{tabular}{|c|c|c|c|c|c|c|}
\hline & \multicolumn{2}{|c|}{ UK } & \multicolumn{2}{|c|}{ Germany } & \multicolumn{2}{|c|}{ Italy } \\
\hline & 2007 & 2012 & 2007 & 2011 & 2007 & 2012 \\
\hline $\begin{array}{l}\text { Newspapers } \\
\text { and Magazines }\end{array}$ & \multicolumn{2}{|c|}{$43.320 .7(-22.6 \%)$} & \multicolumn{2}{|c|}{$58.231 .9(-26.3 \%)$} & \multicolumn{2}{|c|}{$32.530 .9(-1.6 \%)$} \\
\hline Television & & & 22.1 & 39.1 & 53.2 & 47.8 \\
\hline Internet & \multicolumn{2}{|c|}{$10.936 .9(+26.0 \%)$} & \multicolumn{2}{|c|}{$8.719 .2(+10.5 \%)$} & \multicolumn{2}{|c|}{$3.29 .0(+5.8 \%)$} \\
\hline Radio & 3.7 & 3.8 & 3.7 & 4.9 & 7.0 & 6.2 \\
\hline Outdoors & 5.6 & 6.6 & 4.4 & 3.5 & 3.6 & 5.4 \\
\hline Cinema & 1.6 & 1.5 & 0.6 & 1.4 & 0.7 & 0.6 \\
\hline
\end{tabular}

* Author's elaboration of data from Wan, Warc, Bvdv, and Agcom. Data for Germany refers to 2011.

In 2007, in both Germany and the UK, the press was not only the principal segment, but it was also the dominant segment. In fact, in the UK, newspapers and magazines grabbed more than $40 \%$ of the media advertising resources, whereas in Germany nearly $60 \%$ of advertising expenditure went to print media. These comparative data clearly show that with the exception of Italy, where the division of media expenditures has not significantly changed over time, a considerable amount of resources has shifted from print media to the Internet over a five-year period. This shift, however, does not automatically result in a loss of resources for newspaper publishers because a significant portion of Internet advertising expenditures goes toward online versions of print magazines and newspapers. Germany has also experienced a marked rise in the resources invested in television advertising, whereas the Italian media system is one in which television continues to play a leading role and in which the Internet has experienced limited growth.

\subsection{The Press: Key Players}

The pluralism principle can assume significantly different meanings depending on the media sector to which it applies. For example, the vast majority of Western television systems are characterized by a marked tendency toward ownership concentration, which generally translates into systems that are dominated by a limited number of key multimedia players. As the structural features of the press are considerably different from those of TV, the very way in which pluralism is implemented in the press system varies as well. The press system has two main characteristics: a less marked tendency toward ownership concentration and a strong orientation toward "the local level." In fact, aside from a limited number of newspapers having national and worldwide circulation, the majority of newspapers are locally circulated. The ways in which competition takes place in the press market can 
therefore be vary widely depending on which level - regional or national - one refers to. Thus, a press system that enjoys an adequate degree of plurality at the national level may well experience the establishment of (semi)monopolistic conditions at the local level, as Czepek and Klinger (2010) have interestingly shown.

The following table shows the ten most widely distributed newspapers and their publishers in the UK, Germany, and Italy to pinpoint potential differences in the degree of structural pluralism among these three press markets.

Table 3. The ten most widely distributed newspapers per country.

\begin{tabular}{|c|c|c|c|}
\hline & Newspaper & Publisher & Circulation \% \\
\hline \multirow[t]{11}{*}{ UK } & The Sun & News International & 20.3 \\
\hline & The Daily Mail & Associated Press & 14.6 \\
\hline & Daily Mirror & Trinity Mirror & 9.3 \\
\hline & The Daily Telegraph & Telegraph Media Group & 5.6 \\
\hline & Daily Express & Northern\&Shell & 5.0 \\
\hline & Daily Star & Northern\&Shell & 4.8 \\
\hline & The Times & News International & 4.1 \\
\hline & Financial Times & Financial Times Ltd & 3.0 \\
\hline & The Daily Record & Trinity Mirror & 2.6 \\
\hline & The Guardian & Guardian Newspapers & 2.4 \\
\hline & Subtotal & & 71.8 \\
\hline \multirow[t]{11}{*}{ Germany } & Bild & Axel Springer & 15.2 \\
\hline & WAZ-Mediengruppe & Verlagsrguppe WAZ & 4.2 \\
\hline & Zeitungsgruppe Koln & M. DuMont & 2.7 \\
\hline & Suddeutsche Zeitung & German Suddeutscher Verlag & 2.2 \\
\hline & Frankfurter Allgemeine Zeitung & German Verlag & 1.9 \\
\hline & Rheinische Post & German Rheinische Post & 1.9 \\
\hline & Augsburger Allgemeine & German Presse-Druck-und Verlags & 1.7 \\
\hline & Zeitungsgruppen Thuringen & German Zeitungsgruppe Thüringen & 1.6 \\
\hline & fp Freie Presse & German Chemnitzer Verlag & 1.5 \\
\hline & Nurnberger Nachrichten & German Mitteldeutsches & 1.5 \\
\hline & Subtotal & & 34.4 \\
\hline \multirow[t]{11}{*}{ Italy } & Corriere della Sera & RCS Media Group & 5.7 \\
\hline & La Repubblica & Gruppo L'Espresso & 5.2 \\
\hline & La Gazzetta dello Sport & RCS Media Group & 3.8 \\
\hline & La Stampa & Editrice La Stampa & 3.3 \\
\hline & Il Sole 24 ore & Il Sole 24 Ore & 3.1 \\
\hline & Il Messaggero & Il Messaggero & 2.2 \\
\hline & Corriere dello Sport & Corriere Sport & 2.2 \\
\hline & Il Giornale & Europea Edizioni & 2.1 \\
\hline & Il Resto del Carlino & Poligrafici Editoriale & 1.7 \\
\hline & La Nazione & Poligrafici Editoriale & 1.4 \\
\hline & Subtotal & & 30.8 \\
\hline
\end{tabular}

Source: World Association of Newspapers, 2012, 2009. Data for UK refers to 2009.

In the UK, Murdoch's News Corporation is the main shareholder of BSkyB, the satellite TV network that draws the highest annual revenue. Additionally, News Corporation owns News International, the largest newspaper publisher in Britain, printing important papers such as The Times and the tabloid The Sun, which is the most read newspaper in the UK with nearly 3 million copies circulated daily (20.3\%). These data are particularly significant considering that Italian newspapers have an overall circulation of slightly more than 5 million copies. In addition to News International, another player on the British press market is worth mentioning: Northern \& Shell. Not only does Northern \& Shell publish the Daily Express and the Daily Star, but it also owns Five, one of the most important public service networks. The top ten also includes two newspapers - the Daily Mirror and The Daily Record - owned by Trinity Mirror.

In Germany, the leading company is Axel Springer, one of the major publishers in Europe, having interests in numerous countries. Springer owns Bild, a newspaper with an average daily circulation of 2.9 million copies. Overall, the print outlets owned by Springer have a total average circulation of 4.2 million copies per day 
(Kleinsteuber, 2004), 1 million fewer copies than the Italian press's overall circulation. In the past, Springer also split ownership of Sat.1, a satellite TV network, with Leo Kirch's group.

The degree of pluralism achieved in these three press systems illustrates how differently such systems are structured. Indeed, while the ten most widely distributed newspapers in Britain reach an overall circulation of $71.8 \%$, Germany's top papers reach less than half that rate with an overall circulation of $34.4 \%$. Such figures reveal a distinguishing characteristic of the German press: with the important exception of Bild, which is the only German newspaper with a truly national circulation, newspapers are only circulated in locally circumscribed areas. This distinguishing factor generates a press system that is characterized by a comparatively massive number of titles, 353 as opposed to 112 in the UK and 95 in Italy, with very low circulation rates because of their strong local orientation. The notable differences between the British and German press systems can also be detected in the strength of the main publishers. As seen in the UK, big companies such as News International, Northern \& Shell, and Trinity Mirror are owners of more than one newspaper among the ten most circulated. In Germany, however, because of the regionalized organization of the press market, no company owns more than one newspaper among the ten most circulated. The overall pluralism of the German press system is therefore sheltered from potential threats because different newspapers in different regions tend to be owned by different players.

Regarding the Italian print media system, it is worth repeating a caveat: the dimensions of the Italian press market are considerably smaller than those in the UK and Germany. Such a gap necessarily has significant effects on the number of players in that market, which is primarily dominated by two actors: RCS Media Group and the Gruppo Espresso. The first group publishes two of the major newspapers in Italy: Corriere della Sera and sports paper Gazzetta dello Sport. Gruppo Espresso's main outlet is la Repubblica. Unlike in the UK, however, in Italy the joint ownership of TV and daily print outlets is forbidden by law, which seems to have a positive impact on the degree of pluralism in the press system. The ten most widely distributed newspapers are owned by eight different publishers and reach an overall circulation of $30.8 \%$. Interestingly, the press, because of its structural features, which strongly differentiate it from the audiovisual media, seems to have natural antibodies against ownership concentration. Even in a small market like Italy's, the number of players is relatively high. However, in the very same way as the broadcasting sector (Ciaglia, 2013), the Italian press system displays more elements of fragility when compared with other similar European democracies.

\subsection{Trust in the Press}

Before addressing the question of trust in the media, it must be noted that trust, as well as most human feelings, very much depends on the historical circumstances under which it is measured and the nature of the core values that are at the basis of any national context. That said, Figure 2 reveals an unequivocal scenario: three major European countries have extremely high levels of mistrust toward the main traditional media.

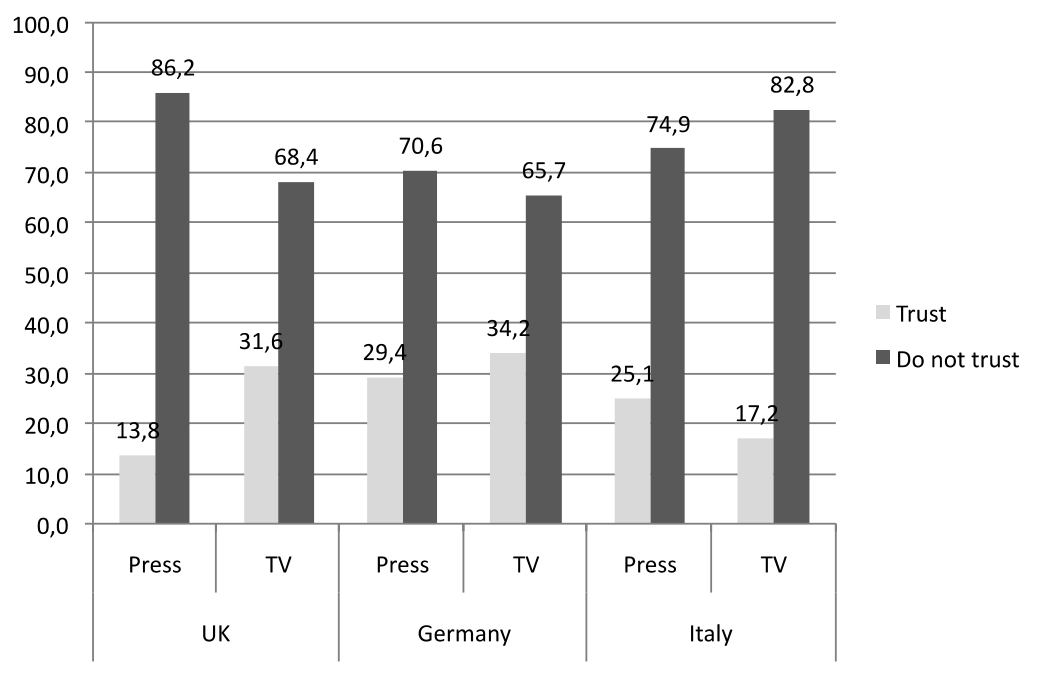

Figure 2. Level of trust in the media, 2008.

Source: World Values Survey 
Indeed, with a slight difference between television and the press, the (traditional) media systems of these three countries share a generalized climate of mistrust. Regardless of the medium, the proportion of citizens who declare themselves to be skeptical toward media credibility is significantly high. In the UK, $86.2 \%$ of this sample declares that they tend not to trust national newspapers. In Italy, skeptical citizens account for nearly three quarters of the total. Germany displays the lower level of mistrust in the press (70.6\%). Nevertheless, such a proportion is still well beyond the threshold of 50\%. Notably, although television is also characterized by a prevalent climate of skepticism, the proportions tend to differ slightly in each country. In Italy - where television is the dominant medium $-82.8 \%$ of those polled believe that television is not credible. Theoretically, one of the best explanations for such a figure may lie with the anomalous conflict of interests embodied in the figure of Silvio Berlusconi. Regardless, in other countries- where threats to TV pluralism are much less anomalous in nature - a generalized climate of mistrust is also prevailing. In the UK, $68.4 \%$ of those polled have mistrust in TV, similar to $65.7 \%$ mistrust in Germany. Therefore, with European citizens displaying worryingly high levels of mistrust, Germany is the country where people's skepticism is less marked. However, the UK and Italy set themselves apart for extremely significant levels of mistrust, particularly in the press and in TV, respectively. Ironically, the medium that dominates in the media market (the press in the UK and TV in Italy) performs quite poorly in terms of credibility and trust.

This irony may be seen, however, as proof that the majority of citizens are sufficiently aware of their respective media systems' shortcomings. In Italy, as already noted, an important role may be played by the citizens' acknowledgement of the mass media's long-standing tendency to act and operate according to the logic of politico-ideological belonging. Such a tendency sees its climax in the Berlusconi phenomenon. With regard to the UK, the high degree of mistrust in the press might be connected to the propensity for scandal, which characterizes the British press and the tabloids in particular. Such factors lead a considerable number of Britons to consider TV more credible than print media. Furthermore, a relevant role may be played not only by the scandalous coverage that the British press provides but also by the scandals embroiling the newspapers themselves. One such example is the case of the 2011 phone hacking scandal involving News of the World, a tabloid owned by Murdoch's News International that closed after the scandal's outbreak. Murdoch's tabloid was accused of violating citizens' rights to privacy and making improper use of wiretappings. The scandal almost involved Scotland Yard and the Prime Minister, given that the former director of News of the World, Andy Coulson, had previously been communications director on David Cameron's staff. This event led to a parliamentary inquiry and Rupert Murdoch's questioning by the competent committee.

\section{Conclusions}

This study has revealed that today's media struggle to validate themselves as credible tools to connect political systems and citizens. It is extremely unlikely that a single reason can ably explain such a marked tendency. This article aimed to elucidate and advance possible explanations for citizens' general mistrust of the press. The explanations explored in the article are specifically related and limited to how particular European press systems are structured and organized. One important result of this research lies in the identification of a paradox. Unlike other media outlets, in particular audiovisual media, the press shows a natural tendency to achieve sufficiently safe levels of structural pluralism. This propensity is mostly due to the structural characteristics of the press market, which allow potential new players to enter the market without having to climb exceedingly high barriers. Nevertheless, despite a sufficient degree of pluralism within the European press systems, the citizens of Germany and the UK tend to consider television to be a much more credible source of information than do Italian citizens. The data relating to Italian media strongly convey its exceptionalism within both Europe and the Western world - an exceptionalism embodied in the figure of Silvio Berlusconi and his conflicts of interest. Indeed, Berlusconi is the leader of the principal right-wing political party, the former prime minister, and the main shareholder of Italy's largest commercial network. The perception of such a profound and rooted anomaly necessarily results in undermining Italian citizens' views of the credibility of their television system.

However, in addition to how the media system is structured, other explanations exist for the generalized and deep skepticism that characterizes three of Europe's largest democratic audiences. Such explanations will require further research to be exhaustively examined and explained. However, as the Italian case suggests, one of the reasons behind citizens' disaffection is the perception of extreme closeness between the political and media systems. Political and institutional actors often play a leading role in shaping today's media systems. In so doing, politics is able to strongly affect the transformative process of contemporary media environments. Such closeness between the two systems does not necessarily translate into partisan coverage from the media. In fact, within media systems that are historically characterized by a strong and marked orientation toward media objectivity and impartiality, the media-politics proximity can take the shape of scandals, as the News of the World 
case shows. However, although the forms through which politics and the media interact can and do vary, the collision of these two worlds always results in growing mistrust of the media's ability to properly play the role of democratic guardians.

\section{References}

Bennett, S. E., Rhine, S. L., Flickinger, R. S., \& Bennett, L. (1999). "Video Malaise" Revisited. Public Trust in the Media and Government. The Harvard International Journal of Press/Politics, 4(5), 8-23. http://hij.sagepub.com/content/4/4/8.abstract

Blumler, J. G., \& Gurevitch, M. (1995). The Crisis of Public Communication. London: Routledge.

Blumler, J. G., \& Kavanagh, D. (1999). The third age of political communication: influences and features. Political Communication, 16, 209-30. http://www.tandfonline.com/doi/abs/10.1080/105846099198596

Campus, D. (2008). Comunicazione politica. Le nuove frontiere. Rome-Bari: Laterza.

Cappella, J. N., \& Jamieson, K. (1997). Spiral of Cynicism. The Press and the Public Good. New York, NY: Oxford University Press.

Ciaglia, A. (2013). Pluralism of the system, pluralism in the system: Assessing the nature of media diversity in two European Countries. The International Communication Gazette, 4(75), 410-26. http://gaz.sagepub.com/content/75/4/410.full.pdf $+\mathrm{html}$

Cook, T. E. (1997). Governing with the News: the news media as a political institution Chicago, IL: Chicago University Press.

Czepek, A., \& Klinger, U. (2010). Media Pluralism between Market Mechanisms and Control: The German Divide. The International Journal of Communication, 4, 820-44. http://ijoc.org/index.php/ijoc/article/view/794/461

Dahl, R. A. (1967). The City in the Future of Democracy. American Political Science Review, 4, 953-70.

Easton, D. (1979). A Framework for Political Analysis. Chicago, IL: The University of Chicago Press.

Easton, D. (1975). A Re-Assessment of the Concept of Political Support. British Journal of Political Science, 5(4), 435-57. URL: http://journals.cambridge.org/action/displayAbstract?fromPage=online\&aid=3332884

Floss, D. (2008). Mass Media's Impact on Confidence in Political Institutions: The Moderating Role of Political Preferences. Working paper 26, National Centre of Competence in Research (NCCR), Challenges to Democracy in the 21 st Century, Zurich.

Gurevitch, M., \& Blumler, J. G. (2004). State of the art of political communication research: Poised for maturity? In F. Esser \& B. Pfetsch (Eds.). Comparing Political Communication: Theories, Cases, and Challenges (pp. 325-43). New York, NY: Cambridge University Press.

Hallin, D. C., \& Mancini, P. (Eds.) (2012). Comparing Media Systems Beyond the Western World. New York, NY: Cambridge University Press.

Hallin, D. C., \& Mancini, P. (2004). Comparing Media Systems: Three Models of Media and Politics. New York, NY: Cambridge University Press.

Kleinsteuber, H. J. (2004). Germany. In M. Kelly, G. Mazzoleni, \& D. McQuail (Eds.). The Media in Europe. The Euromedia Research Group (pp. 78-90). London: Sage.

Newton, K. (1999a). Mass Media Effects: Mobilization or Media Malaise?. British Journal of Political Science, 29, 577-99. URL: http://journals.cambridge.org/action/displayAbstract?fromPage=online \&aid=1415

Newton, K. (1999b). Social and Political Trust in Established Democracies. In P. Norris (Ed.). Critical Citizens. Global Support for Democratic Governance (pp. 169-87). Oxford: Oxford University Press.

Norris, P. (2000). A Virtuous Circle. Political Communications in Postindustrial Societies. New York, NY: Cambridge University Press.

Norris, P. (1996). Does Television Erode Social Capital? A Reply to Putnam. PS: Political Science and Politics, 29(3), 474-80.

Patterson, T. E. (1993). Out of Order. New York: Alfred Knopf.

Pfetsch, B., \& Esser, F. (2004). Comparing political communication: Reorientations in a changing world. In F. Esser \& B. Pfetsch (Eds.). Comparing Political Communication: Theories, Cases, and Challenges (pp. 3-23). New York, NY: Cambridge University Press. 
Postman, N. (1986). Amusing Ourselves to Death: Public Discourse in the Age of Show Business. London: Methuen.

Putnam, R. (2000). Bowling Alone: The Collapse and Revival of American Community. New York, NY: Simon \& Schuster.

Putnam, R. (1995). Bowling Alone: America's Declining Social Capital. Journal of Democracy, 1(6), 65-78. http://muse.jhu.edu/login?auth=0\&type=summary\&url=/journals/journal_of_democracy/v006/6.1putnam.ht $\mathrm{ml}$

Robinson, M. J. (1976). Public Affairs Television and the Growth of Political Malaise: The Case of "The Selling of the Pentagon". American Political Science Review, 2, 409-32. http://www.jstor.org/discover/10.2307/1959647?uid=3738032\&uid=2\&uid=4\&sid=21102627049101

Schudson, M. (2002). The News Media as Political Institutions. Annual Review of Political Science, 5, $249-69$. http://www.annualreviews.org/doi/abs/10.1146/annurev.polisci.5.111201.115816?journalCode=polisci

Siebert, F. S., Peterson, T., \& Schramm, W. (1956). Four Theories of the Press: The Authoritarian, Libertarian, Social Responsibility and Soviet Communist of What the Press Should Be and Do. Urbana, IL: University of Illinois Press.

\section{(c) EY}

This work is licensed under a Creative Commons Attribution 3.0 License. 